\title{
COMMUNICATIONS
}

\section{CALIBRE CHANGES IN RETINAL VESSELS OCCURRING IN RAISED OCULAR TENSION* CIRCULATORY COMPENSATION IN CHRONIC GLAUCOMA}

BY

\section{J. H. DOBREE}

From the Glaucoma Clinic, Institute of Ophthalmology, University of London Director of Research: Sir Stewart Duke-Elder

THE problem is an old one; it is that of the manner in which the intra-ocular blood flow is maintained, often with surprising efficiency of retinal function, in the face of raised ocular tension. The extent to which the intra-ocular circulation can continue in extreme degrees of tension was dramatically demonstrated by Hill and Flack (1912). These workers divided a vortex vein of a cat and then raised the ocular pressure by means of a needle connected to a water manometer. They found that it was necessary to increase the ocular tension until it approximated to that of the carotid before the uveal circulation was finally arrested.

Of the several factors which influence the blood flow in conditions of raised pressure, that of the changes occurring in the arterial and venous pressures has received the most attention. Hill and Flack (1912), Hill (1913), Starling (1913), and others, showed that in conditions of raised ocular tension the venous pressure must always be slightly higher than the ocular pressure if the circulation is to be maintained. Duke-Elder (1926) elucidated the fundamental relationship between the ocular and vascular pressures. He stated that any increase in ocular pressure tends to compress the veins at their points of exit, the vis a tergo from the arteries then piles up pressure and forces past the obstruction, and the intra-ocular circulation proceeds at a higher level. If the ocular pressure increases further, this process repeats itself until the available force from the arteries is exhausted, that is, until the pressure in the ophthalmic artery is reached.

Clinical observations support the experimental work. Using the ophthalmo-dynamometer, Bailliart (1922) and Bailliart and Magitot (1925) found that in chronic glaucoma there was a great increase in the venous pressure and a moderate increase in the arterial pressure. Weinstein (1935) noted an increased pressure in the pre-capillaries in chronic glaucoma, and Espildora-Luque (1948), summarizing some of his previous work, recorded that in several cases he found a reduction in the vascular pressures after the tension had been lowered by miotics or by operation.

It has been established, therefore, that there is a local rise of both arterial

*Received for publication September 2, 1955. 
and venous pressures whenever the ocular pressure is raised and this enables an adequate pressure-gradient, or difference in pressure between the intraocular arteries and intra-ocular veins, to maintain a sufficient blood flow through the eye. The quantity of blood flowing in unit time (or volume flow) does not, however, depend solely on the height of the pressure-gradient. Other factors play a part, notably the vascular resistance. This is the resistance to the flow of blood through the arteries, capillaries, and veins; the most important element of which it is composed is the calibre of the vessels themselves, particularly that of the arterioles.

Poiseuille's formula relates the factors which influence the volume of fluid passing through tubes of uniform bore in a given time. Providing the pressure-gradient remains constant, the volume flow varies as the 4th power of the radius of the tube. This means that a small variation in the bore results in a considerable variation in volume flow. For example, an incresse in calibre of 20 per cent. will result in an increase of over 100 per cent. in the volume of fluid passing through a tube in a given time. The formula cannnt. be applied directly to the problem in question as many of the requirements. (uniform calibre, no branching, streamlined flow, etc.) are not met." It." is. clear, however, that even minor alterations in the calibre of the vessels, especially those on the arterial side, must profoundly alter the vascular resistance and hence the volume flow.

The diameters of the intra-ocular vessels in glaucoma have not been adequately investigated. There are several isolated allusions to the calibres of the retinal vessels in chronic glaucoma and these are contradictory, possibly in part for the reason that the corresponding ocular pressures are not specified. Bailliart (1935), for example, states that in chronic glaucoma both retinal arteries and veins are narrowed; Duke-Elder (1940), writing of chronic congestive glaucoma, states that retinal veins are engorged. Furthermore, these writers do not state whether they are considering blind eyes or those in which retinal function is present.

Interest in the question of possible alterations that might occur in the the intra-ocular vessels was aroused by the finding (Dobree, 1954) that there is considerable dilatation of the anterior ciliary arteries in conditions of chronically raised ocular pressure.

A preliminary series of observations was made by means of a graticưf ic in a fundus-measuring ophthalmoscope. It soon became clear that apart from those occurring in very high tensions the calibre variations encopntered were not great and that a more accurate method of measurement wass de-sirable. Fundus photography was eventually employed to record the changegs in calibre of the retinal vessels in a series of cases with differing degrefs of rassed ocular tension.

Clinical Material

Patients.-Thirteen eyes of eleven patients were examined. Twelve of thid eyjes were from patients suffering from chronic glaucoma simplex and one from a 
patient with juvenile glaucoma. Cases were divided into four groups according to the tension at the time of the initial photographs, as follows:
(1) Tension over $60 \mathrm{~mm} . \mathrm{Hg}$
(Three)
(2) Tension between 50 and $60 \mathrm{~mm} . \mathrm{Hg}$ (Four)
(3) Tension between 40 and $50 \mathrm{~mm} . \mathrm{Hg}$ (Three)
(4) Tension below $40 \mathrm{~mm}$. $\mathrm{Hg}$
(Three)

As it was necessary to dilate the pupils in order to photograph the fundus vessels, the width of the angles was confirmed by gonioscopy and only eyes possessing wide or medium angles were included.

Particular care was taken to exclude any case in which there was any ciliary congestion. As is commonly found in cases of chronic simple glaucoma (Sugar, 1951) the eyes were macroscopically white.

It was particularly desired to examine the fundus vessels in eyes in which there was a functioning retina, rather than a blind eye in which the vessels were passing through a functionless pressure chamber. Accordingly the vision in the selected eyes had to reach a standard of $6 / 36$, or better. The visual fields were restricted in some cases, but both these and the visual acuity were virtually unchanged before and after reduction of pressure.

As it was thought that the state of the general circulation influences the local ocular vascular reactions, the systemic B.P. was taken in all cases and an assessment of the degree of arteriosclerosis of the retinal vessels made (the implication of this is discussed later).

The details of the selected cases are set out in Table I.

TABLE I

\section{CLINICAL DETAILS OF TEST CASES}

(Patients in order of age)

\begin{tabular}{|c|c|c|c|c|c|c|c|c|c|}
\hline $\begin{array}{l}\text { Case } \\
\text { No. }\end{array}$ & Sex & Age & $\begin{array}{c}\text { Blood Pressure } \\
(\mathrm{mm} . \mathrm{Hg})\end{array}$ & Eye & $\begin{array}{l}\text { Visual } \\
\text { Acuity }\end{array}$ & $\begin{array}{l}\text { Visual Field } \\
\text { 1/330 White } \\
\text { (min.-max.) }\end{array}$ & $\begin{array}{c}\text { Initial } \\
\text { Tension } \\
\text { (mm. Hg) }\end{array}$ & $\begin{array}{l}\text { Method of } \\
\text { reducing tension }\end{array}$ & $\begin{array}{c}\text { Final } \\
\text { Tension } \\
(\mathrm{mm} . \mathbf{H g})\end{array}$ \\
\hline 1 & $\mathbf{M}$ & 65 & $150 / 80$ & L & $6 / 24$ & $10^{\circ}-30^{\circ}$ & 77 & Operation & 22 \\
\hline 2 & F & 55 & $150 / 80$ & $\mathbf{R}$ & $6 / 9$ & $5^{\circ}-40$ & 73 & Operation & 22 \\
\hline 3 & F & 71 & $145 / 80$ & L & $6 / 36$ & $7^{\circ}-10^{\circ}$ & 67 & Operation & 31 \\
\hline 4 & $\mathbf{M}$ & 31 & $124 / 80$ & L & $6 / 12$ & $20^{\circ}-50^{\circ}$ & 55 & Operation & 40 \\
\hline \multirow{2}{*}{5} & \multirow{2}{*}{$\mathbf{M}$} & \multirow{2}{*}{56} & \multirow{2}{*}{$170 / 90$} & $\mathbf{R}$ & $6 / 6$ & $2^{\circ}-90^{\circ}$ & 51 & $\left\{\begin{array}{c}\text { Pilocarpine } \\
\text { Diamox }\end{array}\right.$ & 31 \\
\hline & & & & L & $6 / 5$ & $40^{\circ}-80^{\circ}$ & 31 & $\left\{\begin{array}{c}\text { Pilocarpine } \\
\text { Diamox }\end{array}\right.$ & 26 \\
\hline 6 & $\mathbf{M}$ & 52 & $160 / 80$ & $\mathbf{L}$ & $6 / 9$ & $5^{\circ}-80^{\circ}$ & 51 & Pilocarpine & 31 \\
\hline 7 & $\mathbf{M}$ & 54 & $170 / 104$ & $\mathbf{R}$ & $6 / 6$ & $45^{\circ}-85^{\circ}$ & 51 & Pilocarpine & 27 \\
\hline 8 & $\mathbf{F}$ & 50 & $176 / 90$ & $\mathbf{R}$ & $6 / 6$ & $40^{\circ}-90^{\circ}$ & 45 & Pilocarpine & 31 \\
\hline 9 & $\mathbf{F}$ & 50 & $170 / 110$ & $\mathbf{L}$ & $6 / 9$ & $40^{\circ}-85^{\circ}$ & 45 & Operation & 30 \\
\hline \multirow[t]{2}{*}{10} & \multirow[t]{2}{*}{$\mathbf{M}$} & \multirow[t]{2}{*}{72} & \multirow{2}{*}{$180 / 100$} & $\mathbf{R}$ & $6 / 6$ & $45^{\circ}-90^{\circ}$ & 40 & $\left\{\begin{array}{c}\text { Pilocarpine } \\
\text { Diamox }\end{array}\right.$ & 30 \\
\hline & & & & $\mathbf{L}$ & $6 / 6$ & $45^{\circ}-80^{\circ}$ & 33 & $\left\{\begin{array}{c}\text { Pilocarpine } \\
\text { Diamox }\end{array}\right.$ & 30 \\
\hline 11 & $\mathbf{F}$ & 76 & $174 / 00$ & $\mathbf{R}$ & $6 / 9$ & $40^{\circ}-50^{\circ}$ & 25 & Pilocarpine & 20 \\
\hline
\end{tabular}


Controls.-Seven control eyes were examined. Case 1 was a glaucomatous eye which had the same tension $(50 \mathrm{~mm}$. $\mathrm{Hg}$ ) both before and after an unsuccessful filtering operation. Cases 2 and 3 were the two eyes of a patient suffering from pseudo-glaucoma. These were with marked progressive arcuate field defects but no rise of tension had ever been found over an observation period of some 4 years; the photographs in this case were taken at an interval of 6 months. The four others were normal eyes but were subjected to the same miotic and photographic routine as the glaucomatous cases. The controls came from similar age groups to the test series and none had any evidence of generalized vascular disease.

\section{Procedure}

The initial photographs were taken either before any form of treatment had been given or, in those patients who were on miotics, after these had been withheld for 24 hours. The fundus photographs were taken with a Nordensen camera on $35 \mathrm{~mm}$. colour film. The time of the actual photography in all cases was between 11.30 a.m. and 12.30 p.m. The reason for limiting the time was to ensure that should a diurnal calibre variation occur in the retina as it does in the episclera (Dobree, 1953; Kleinert, 1954) it would tend to be present both before and after reduction of tension to the same degree. Dilatation of the pupil was effected by 1 per cent. homatropine (without cocaine) in every case, and the tension was checked by a Schiötz X tonometer before and after the photograph. In one eye only was there any appreciable rise in tension after homatropine and in this case it was rapidly reduced by miotics. This experience of the effect of homatropine on the tension in.simple glaucoma is similar to that of Kronfeld and others (1943) and Sugar (1948).

The second photograph, showing the condition of the retinal vessels when the tension had been lowered, was taken after the pressure had been well stabilized. In the cases in which the reduction of tension had been effected by operation a month was allowed to elapse before the photograph was taken. In cases in which the tension was lowered by 2 per cent. pilocarpine this was given three times daily for 1 or 2 weeks including the same morning as the photograph was taken. In both sets of cases 1 per cent. homatropine was used as before. Even although pilocarpine had been given some 1 or 2 hours previously in some cases, sufficient dilatation was obtained to get good fundus photographs.

No change in vessel calibre was accepted as such unless it were in clear focus in both photographs. Each pair was first examined to ensure that the same magnification of the fundus camera had been used on each occasion. This was done quite simply by superimposing the two transparencies and making sure that all points coincided.

The transparencies were then placed on a microscope stage and selected vessels in good focus from each pair measured by an eye-piece micrometer at a magnification of 54 diameters. Where possible the main, upper, and lower temporal vessels were chosen, but in some cases if one group was not in sufficiently good focus the corresponding nasal vessels were substituted. A third vessel was also taken if the first two showed differences in behaviour. The actual site selected for measurement was between 0.5 and 1 disc diameter from the disc, at a site which could easily be identified on each photograph and where the calibre was regular. The reason for choosing a site some distance from the disc was to ensure as far as possible that vascular pulsations, which are always most marked on the disc itself, had 
not entered the picture. (It turned out that, as the pulsations are more marked at the higher levels of intra-ocular pressure, any that did occur would have lessened rather than increased the calibre differences found). 26 pairs of arteries and 26 pairs of veins were measured on the test series, and ten pairs of arteries and thirteen pairs of veins in the control series.

Each vessel was measured eight times by the eye-piece micrometer, and the standard error, mean diameter, and percentage difference in diameter between each pair of vessels were calculated. A significance level of 1 per cent. was chosen; the significant differences in the vessel diameters at the 1 per cent. level are marked with an asterisk in Tables II to V.

TABLE II

CHANGES IN ARTERIAL CALIBRE

(Eyes in order of degree of tension)

\begin{tabular}{|c|c|c|c|c|c|c|}
\hline \multirow{2}{*}{ Case No. } & \multirow{2}{*}{ Eye } & \multirow{2}{*}{$\begin{array}{c}\text { Tension } \\
\text { (mm. Hg) }\end{array}$} & \multirow{2}{*}{ Artery } & \multicolumn{2}{|c|}{ Calibre } & \multirow{2}{*}{$\begin{array}{l}\text { Per cent. } \\
\text { Difference }\end{array}$} \\
\hline & & & & High Tension & Low Tension & \\
\hline 1 & $\mathbf{L}$ & 77 & UT & $29 \cdot 75 \pm \cdot 47$ & $24 \cdot 25 \pm \cdot 36$ & $-18 \cdot 5^{*}$ \\
\hline .2 & $\mathbf{R}$ & 73 & $\begin{array}{l}\text { UT } \\
\text { LT }\end{array}$ & $\begin{array}{l}20 \cdot 37 \pm \cdot 18 \\
24 \cdot 50 \pm \cdot 18\end{array}$ & $\begin{array}{l}15 \cdot 37 \pm \cdot 18 \\
19 \cdot 37 \pm \cdot 26\end{array}$ & $\begin{array}{l}-24 \cdot 6^{*} \\
-21 \cdot 3^{*}\end{array}$ \\
\hline 3 & $\mathbf{L}$ & 67 & $\begin{array}{l}\text { LT } \\
\text { UN }\end{array}$ & $\begin{array}{l}19 \cdot 00 \pm \cdot 26 \\
20 \cdot 30 \pm \cdot 18\end{array}$ & $\begin{array}{l}14 \cdot 37 \pm \cdot 18 \\
15 \cdot 60 \pm \cdot 18\end{array}$ & $\begin{array}{l}-24 \cdot 4^{*} \\
-23 \cdot 4^{*}\end{array}$ \\
\hline 4 & $\mathrm{~L}$ & 55 & $\begin{array}{l}\text { UT } \\
\text { LT } \\
\text { UN }\end{array}$ & $\begin{array}{l}31 \cdot 00 \pm \cdot 19 \\
26 \cdot 37 \pm \cdot 18 \\
24 \cdot 87 \pm \cdot 13\end{array}$ & $\begin{array}{l}31 \cdot 12 \pm \cdot 22 \\
23 \cdot 87 \pm \cdot 23 \\
22 \cdot 88 \pm \cdot 12\end{array}$ & $\begin{array}{l}+0.4 \\
-9.5^{*} \\
-8.0^{*}\end{array}$ \\
\hline 5 & $\mathbf{R}$ & 51 & $\begin{array}{l}\text { UT } \\
\text { LT }\end{array}$ & $\begin{array}{l}26 \cdot 81 \pm \cdot 29 \\
30 \cdot 00 \pm \cdot 18\end{array}$ & $\begin{array}{l}25 \cdot 62 \pm \cdot 26 \\
25 \cdot 00+\cdot 18\end{array}$ & $\begin{array}{l}-4 \cdot 4^{*} \\
-16 \cdot 7^{*}\end{array}$ \\
\hline 6 & $\mathbf{L}$ & 51 & $\begin{array}{l}\text { UT } \\
\text { LT }\end{array}$ & $\begin{array}{l}21 \cdot 87 \pm \cdot 23 \\
19 \cdot 87 \pm \cdot 23\end{array}$ & $\begin{array}{l}21 \cdot 75 \pm \cdot 16 \\
20 \cdot 25 \pm \cdot 18\end{array}$ & $\begin{array}{l}-0.6 \\
+1.9\end{array}$ \\
\hline 7 & $\mathbf{R}$ & 51 & $\begin{array}{l}\text { UT } \\
\text { LT }\end{array}$ & $\begin{array}{l}21 \cdot 00 \pm \cdot 00 \\
24 \cdot 00 \pm \cdot 18 \\
\end{array}$ & $\begin{array}{l}21 \cdot 87 \pm \cdot 23 \\
24 \cdot 63 \pm \cdot 18 \\
\end{array}$ & $\begin{array}{l}+4 \cdot 1^{*} \\
+2 \cdot 6 \\
\end{array}$ \\
\hline 9 & $\mathbf{L}$ & 45 & UT & $23 \cdot 87 \pm \cdot 38$ & $22 \cdot 37 \pm \cdot 37$ & $-6 \cdot 9$ \\
\hline 8 & $\mathbf{R}$ & 45 & $\begin{array}{l}\text { UT } \\
\text { LT }\end{array}$ & $\begin{array}{l}25 \cdot 25 \pm \cdot 18 \\
18 \cdot 87 \pm \cdot 18\end{array}$ & $\begin{array}{l}25 \cdot 00 \pm \cdot 18 \\
19 \cdot 00 \pm \cdot 40\end{array}$ & $\begin{array}{r}-0.9 \\
+0.7\end{array}$ \\
\hline \multirow[t]{2}{*}{10} & $\mathbf{R}$ & 40 & $\begin{array}{l}\text { UT } \\
\text { LT } \\
\text { LN }\end{array}$ & $\begin{array}{l}19 \cdot 00 \pm \cdot 18 \\
21 \cdot 50 \pm \cdot 18 \\
19 \cdot 62 \pm \cdot 18\end{array}$ & $\begin{array}{l}19 \cdot 00 \pm \cdot 26 \\
21 \cdot 50 \pm \cdot 18 \\
20 \cdot 75 \pm \cdot 21\end{array}$ & $\begin{array}{r}.00 \\
.00 \\
+5.7^{*}\end{array}$ \\
\hline & $\mathbf{L}$ & 33 & $\begin{array}{l}\text { UT } \\
\text { LT }\end{array}$ & $\begin{array}{l}20 \cdot 12 \pm \cdot 13 \\
21 \cdot 00 \pm \cdot 00 \\
\end{array}$ & $\begin{array}{l}20 \cdot 25 \pm \cdot 16 \\
21 \cdot 12 \pm \cdot 13\end{array}$ & $\begin{array}{l}+0.6 \\
+0.5\end{array}$ \\
\hline 5 & $\mathbf{L}$ & 31 & $\begin{array}{l}\text { UT } \\
\text { LT }\end{array}$ & $\begin{array}{l}28 \cdot 00 \pm \cdot 19 \\
24 \cdot 50 \pm \cdot 18\end{array}$ & $\begin{array}{l}28 \cdot 40 \pm \cdot 18 \\
25 \cdot 00 \pm \cdot 18\end{array}$ & $\begin{array}{l}-1 \cdot 4 \\
+2.0\end{array}$ \\
\hline 11 & $\mathbf{R}$ & 25 & $\begin{array}{l}\text { UT } \\
\text { LT }\end{array}$ & $\begin{array}{l}25 \cdot 37 \pm \cdot 18 \\
25 \cdot 26 \pm \cdot 18\end{array}$ & $\begin{array}{l}25 \cdot 12 \pm \cdot 13 \\
24 \cdot 87 \pm \cdot 29\end{array}$ & $\begin{array}{l}-1.0 \\
-1.5\end{array}$ \\
\hline
\end{tabular}




\section{(1) Calibre Changes after Reduction in Tension}

\begin{tabular}{|c|c|c|c|c|c|}
\hline \multicolumn{2}{|l|}{ Arteries } & \multicolumn{4}{|c|}{ Veins } \\
\hline Decrease... $\quad \ldots$ & 9) & Decrease... & $\ldots$ & $\ldots$ & 16) \\
\hline Increase $\ldots . \quad \ldots$ & 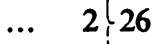 & Increase ... & $\ldots$ & $\ldots$ & 126 \\
\hline No significant change & 15) & No signific & change & $\ldots$ & 7) \\
\hline
\end{tabular}

The calibre reductions were most marked in the eyes having the higher initial tensions and the calibre increases were small. A further analysis of the results in the four tension groups demonstrates these trends:

Arteries (Table II)

Group I (Over $60 \mathrm{~mm}$. Hg initial tension). All five arteries in this group underwent a reduction in calibre varying from 18.5 to 24.6 per cent. on reduction of tension.

Group II (Initial tension between 50 and $60 \mathrm{~mm}$. $\mathrm{Hg}$ ). Of the nine arteries in this group, four underwent a decrease in calibre of 9.5, 8.0, 16.7 and 4.4 per cent. respectively, and one an increase of 4.1 per cent; the other four vessels showed no significant change.

Group III (Initial tension between 40 and $50 \mathrm{~mm}$. $\mathrm{Hg}$ ). None of these five arteries showed a change.

Group IV (Initial tension below $40 \mathrm{~mm}$. $\mathrm{Hg}$ ). One vessel showed an increase of 5.7 per cent.; six showed no significant change.

Control Group (Ten arteries) Table III.-Two arteries showed a change of calibre of 5.8 and 4.4 per cent. respectively, the other eight showed no change. The vessel which showed the change of 5.8 per cent. calibre was the second photograph of one of the two eyes of the patient suffering from pseudoglaucoma, and the one showing a difference of 4.4 per cent. from one of the normal eyes which had been given pilocarpine for a week.

TABLE III

CHANGES IN ARTERIAL CALIBRE

\begin{tabular}{|c|c|c|c|c|c|}
\hline \multirow{2}{*}{ Controls } & \multirow{2}{*}{ Eye } & \multirow{2}{*}{ Artery } & \multicolumn{2}{|c|}{ Photograph } & \multirow{2}{*}{$\begin{array}{l}\text { Per cent. } \\
\text { Difference }\end{array}$} \\
\hline & & & First & Second & \\
\hline $\mathbf{A}$ & $\mathbf{R}$ & UT & $20 \cdot 37 \pm \cdot 18$ & $21 \cdot 12 \pm \cdot 26$ & $3 \cdot 60$ \\
\hline \multirow{2}{*}{ B } & $\mathbf{R}$ & $\begin{array}{l}\text { UT } \\
\text { LN }\end{array}$ & $\begin{array}{l}19 \cdot 25 \pm \cdot 16 \\
15 \cdot 00 \pm \cdot 00\end{array}$ & $\begin{array}{l}20 \cdot 38 \pm \cdot 18 \\
15 \cdot 37 \pm \cdot 18\end{array}$ & $\begin{array}{l}5 \cdot 8^{*} \\
2 \cdot 5\end{array}$ \\
\hline & L & $\begin{array}{l}\text { UT } \\
\text { LT } \\
\text { UN }\end{array}$ & $\begin{array}{l}19 \cdot 87 \pm \cdot 18 \\
20 \cdot 87 \pm \cdot 12 \\
15 \cdot 87 \pm \cdot 12\end{array}$ & $\begin{array}{l}19 \cdot 75 \pm \cdot 16 \\
20 \cdot 64 \pm \cdot 26 \\
16 \cdot 37 \pm \cdot 32\end{array}$ & $\begin{array}{l}\cdot 06 \\
1 \cdot 1 \\
3 \cdot 1\end{array}$ \\
\hline \multirow{2}{*}{ C } & $\mathbf{R}$ & UT & $20 \cdot 00 \pm \cdot 18$ & $20 \cdot 12 \pm \cdot 12$ & 0.6 \\
\hline & $\mathbf{L}$ & UT & $19 \cdot 87 \pm \cdot 22$ & $20 \cdot 75 \pm \cdot 16$ & $4 \cdot 4^{*}$ \\
\hline D & $\mathbf{R}$ & UT & $22 \cdot 25 \pm \cdot 25$ & $22 \cdot 00 \pm \cdot 18$ & $1 \cdot 1$ \\
\hline E & $\mathbf{R}$ & UT & $20 \cdot 87 \pm \cdot 12$ & $19 \cdot 87 \pm \cdot 35$ & $4 \cdot 8$ \\
\hline
\end{tabular}


Veins (Table IV)

Group I (Over $60 \mathrm{~mm}$. Hg initial tension). All six veins in this group $\because \therefore$ underwent a reduction in calibre of between 14.6 and 28.9 per cent.

$: \because \because$ Group II (Between 50 and $60 \mathrm{~mm}$. Hg initial tension). Of the eight veins in this group, four showed a decrease in calibre varying between 8.9 and 19.7 per cent., one showed an increase of 3.6 , and the remaining three $\therefore$ no significant change.

Group III (Between 40-50 mm. $\mathrm{Hg}$ ). Of the six veins in this group, three showed a decrease in calibre varying between 6.7 and 12.2 per cent., one

TABLE IV

\section{CHANGES IN VENOUS CALIBRE}

(Eyes in order of degree of tension)

\begin{tabular}{|c|c|c|c|c|c|c|}
\hline \multirow{2}{*}{ Case No. } & \multirow{2}{*}{ Eye } & \multirow{2}{*}{$\begin{array}{l}\text { Tension } \\
\text { (mm. Hg) }\end{array}$} & \multirow{2}{*}{ Vein } & \multicolumn{2}{|c|}{ Calibre } & \multirow{2}{*}{$\begin{array}{l}\text { Per cent. } \\
\text { Difference }\end{array}$} \\
\hline & & & & High Tension & Low Tension & \\
\hline 1 & $\mathbf{L}$ & 77 & $\begin{array}{l}\text { UT } \\
\text { UN }\end{array}$ & $\begin{array}{l}40 \cdot 25 \pm \cdot 36 \\
33 \cdot 75 \pm \cdot 36\end{array}$ & $\begin{array}{l}30 \cdot 50 \pm \cdot 18 \\
24 \cdot 00 \pm \cdot 26\end{array}$ & $\begin{array}{l}-24 \cdot 2^{*} \\
-28 \cdot 9^{*}\end{array}$ \\
\hline 2 & $\mathbf{R}$ & 73 & $\begin{array}{l}\text { UT } \\
\text { LT }\end{array}$ & $\begin{array}{l}33 \cdot 12 \pm \cdot 29 \\
33 \cdot 12 \pm \cdot 29\end{array}$ & $\begin{array}{l}25 \cdot 75 \pm \cdot 25 \\
24 \cdot 87 \pm \cdot 12\end{array}$ & $\begin{array}{l}-22 \cdot 3^{*} \\
-24 \cdot 1^{*}\end{array}$ \\
\hline 3 & $\mathbf{L}$ & 67 & $\begin{array}{l}\text { UT } \\
\text { UN }\end{array}$ & $\begin{array}{l}24 \cdot 00 \pm \cdot 32 \\
19 \cdot 75 \pm \cdot 16\end{array}$ & $\begin{array}{l}20 \cdot 50 \pm \cdot 26 \\
16 \cdot 00 \pm \cdot 27\end{array}$ & $\begin{array}{l}-14: 6^{*} \\
-18 \cdot 9^{*}\end{array}$ \\
\hline 4 & $\mathbf{L}$ & 55 & $\begin{array}{l}\text { UT } \\
\text { LT }\end{array}$ & $\begin{array}{l}40 \cdot 63 \pm \cdot 26 \\
39 \cdot 37 \pm \cdot 26\end{array}$ & $\begin{array}{l}35 \cdot 63 \pm \cdot 19 \\
35 \cdot 75 \pm \cdot 25\end{array}$ & $\begin{array}{l}-19 \cdot 7^{*} \\
-9 \cdot 0^{*}\end{array}$ \\
\hline 5 & $\mathbf{R}$ & 51 & $\begin{array}{l}\text { UT } \\
\text { LT }\end{array}$ & $\begin{array}{l}35 \cdot 25 \pm \cdot 16 \\
35 \cdot 25 \pm \cdot 16\end{array}$ & $\begin{array}{l}35 \cdot 37 \pm \cdot 09 \\
31 \cdot 12 \pm \cdot 37\end{array}$ & $\begin{array}{l}+0 \cdot 3 \\
-8 \cdot 9^{*}\end{array}$ \\
\hline 6 & $\mathbf{L}$ & 51 & UT & $24 \cdot 37 \pm \cdot 26$ & $24 \cdot 25 \pm \cdot 15$ & -0.5 \\
\hline 7 & $\mathbf{R}$ & 51 & $\begin{array}{l}\text { UT } \\
\text { LT } \\
\text { UN }\end{array}$ & $\begin{array}{l}37 \cdot 75 \pm \cdot 31 \\
41 \cdot 25 \pm \cdot 36 \\
23 \cdot 63 \pm \cdot 18\end{array}$ & $\begin{array}{l}39 \cdot 12 \pm \cdot 22 \\
41 \cdot 50 \pm \cdot 18 \\
24 \cdot 25 \pm \cdot 12\end{array}$ & $\begin{array}{l}+3 \cdot 6^{*} \\
+0.6 \\
+2.6\end{array}$ \\
\hline 9 & $\mathbf{L}$ & 45 & $\begin{array}{l}\text { UT } \\
\text { LT }\end{array}$ & $\begin{array}{l}33 \cdot 37 \pm \cdot 63 \\
33 \cdot 87 \pm \cdot 48\end{array}$ & $\begin{array}{l}31 \cdot 12 \pm \cdot 48 \\
29 \cdot 75 \pm \cdot 25\end{array}$ & $\begin{array}{l}-6 \cdot 7^{*} \\
-12 \cdot 2^{*}\end{array}$ \\
\hline 8 & $\mathbf{R}$ & 45 & UN & $23 \cdot 62 \pm \cdot 18$ & $21 \cdot 87 \pm \cdot 22$ & $-7 \cdot 4^{*}$ \\
\hline \multirow[t]{2}{*}{10} & $\mathbf{R}$ & 40 & $\begin{array}{l}\text { UT } \\
\text { LT } \\
\text { UN }\end{array}$ & $\begin{array}{l}23 \cdot 50 \pm \cdot 18 \\
27 \cdot 87 \pm \cdot 23 \\
19 \cdot 37 \pm \cdot 18\end{array}$ & $\begin{array}{l}23 \cdot 25 \pm \cdot 25 \\
29 \cdot 00 \pm \cdot 18 \\
19 \cdot 87 \pm \cdot 09\end{array}$ & $\begin{array}{l}-1 \cdot 1 \\
+4 \cdot 1^{*} \\
+2 \cdot 6\end{array}$ \\
\hline & $\mathbf{L}$ & 33 & $\begin{array}{l}\text { UT } \\
\text { LT }\end{array}$ & $\begin{array}{l}31 \cdot 50 \pm \cdot 12 \\
24 \cdot 25 \pm \cdot 13\end{array}$ & $\begin{array}{l}29 \cdot 85 \pm \cdot 22 \\
22 \cdot 37 \pm \cdot 13\end{array}$ & $\begin{array}{l}-5 \cdot 5^{*} \\
-7 \cdot 7^{*}\end{array}$ \\
\hline 5 & $\mathbf{L}$ & 31 & $\begin{array}{l}\text { UT } \\
\text { LT }\end{array}$ & $\begin{array}{l}31 \cdot 00 \pm \cdot 18 \\
37 \cdot 50 \pm \cdot 26\end{array}$ & $\begin{array}{l}31 \cdot 25 \pm \cdot 13 \\
38 \cdot 12 \pm \cdot 35\end{array}$ & $\begin{array}{l}+0.8 \\
+1.7\end{array}$ \\
\hline 11 & $\mathbf{R}$ & 25 & $\begin{array}{l}\text { UT } \\
\text { LT }\end{array}$ & $\begin{array}{l}24 \cdot 12 \pm \cdot 29 \\
29 \cdot 62 \pm \cdot 18\end{array}$ & $\begin{array}{l}21 \cdot 25 \pm \cdot 16 \\
24 \cdot 87 \pm \cdot 12\end{array}$ & $\begin{array}{l}-11 \cdot 9^{*} \\
-16 \cdot 2^{*}\end{array}$ \\
\hline
\end{tabular}


showed an increase in calibre of 4.0 per cent. and the remaining two no significant change.

Group IV (Below $40 \mathrm{~mm}$. $\mathrm{Hg}$ ). Of the six veins in this group, four showed a decrease in calibre varying between $5 \cdot 5$ and $16 \cdot 2$ per cent. and the remaining two no significant change.

Control Group (Thirteen veins) Table V.-Only one vein showed a significant change, a difference of 5.8 per cent. This was the eye (of the patient who had pseudo-glaucoma) which also showed an increase in calibre of one of the arteries in the second photograph.

TABLE V

CHANGES IN VENOUS CALIBRE

\begin{tabular}{|c|c|c|c|c|c|}
\hline \multirow{2}{*}{ Control } & \multirow{2}{*}{ Eye } & \multirow{2}{*}{ Vein } & \multicolumn{2}{|c|}{ Photograph } & \multirow{2}{*}{$\begin{array}{l}\text { Per cent. } \\
\text { Difference }\end{array}$} \\
\hline & & & First & Second & \\
\hline $\mathbf{A}$ & $\mathbf{R}$ & $\begin{array}{l}\text { UT } \\
\text { UN }\end{array}$ & $\begin{array}{l}20 \cdot 62 \pm \cdot 12 \\
25 \cdot 12 \pm \cdot 18\end{array}$ & $\begin{array}{l}20 \cdot 37 \pm \cdot 18 \\
25 \cdot 00 \pm \cdot 26\end{array}$ & $\begin{array}{l}1.2 \\
0.5\end{array}$ \\
\hline \multirow{2}{*}{$\mathbf{B}$} & $\mathbf{R}$ & $\begin{array}{l}\text { UT } \\
\text { LT }\end{array}$ & $\begin{array}{l}28 \cdot 50 \pm \cdot 32 \\
32 \cdot 50 \pm \cdot 18\end{array}$ & $\begin{array}{r}29 \cdot 12 \pm \cdot 38 \\
\cdot 34 \cdot 25 \pm \cdot 16\end{array}$ & $\begin{array}{l}2 \cdot 2 \\
5 \cdot 4^{*}\end{array}$ \\
\hline & L & $\begin{array}{l}\text { UT } \\
\text { LT } \\
\text { UN }\end{array}$ & $\begin{array}{l}24 \cdot 50 \pm \cdot 26 \\
28 \cdot 62 \pm \cdot 26 \\
22 \cdot 12 \pm \cdot 12\end{array}$ & $\begin{array}{l}25 \cdot 12 \pm \cdot 22 \\
27 \cdot 50 \pm \cdot 38 \\
21 \cdot 87 \pm \cdot 22\end{array}$ & $\begin{array}{l}2 \cdot 5 \\
3 \cdot 9 \\
1 \cdot 1\end{array}$ \\
\hline \multirow{2}{*}{ C } & $\mathbf{R}$ & $\begin{array}{l}\text { UT } \\
\text { LT }\end{array}$ & $\begin{array}{l}22 \cdot 87 \pm \cdot 34 \\
28 \cdot 12 \pm \cdot 22\end{array}$ & $\begin{array}{l}22 \cdot 75 \pm \cdot 45 \\
28 \cdot 00 \pm \cdot 26\end{array}$ & $\begin{array}{l}0 \cdot 5 \\
0 \cdot 4\end{array}$ \\
\hline & $\mathbf{L}$ & UT & $22 \cdot 12 \pm \cdot 40$ & $21 \cdot 75 \pm \cdot 25$ & $1 \cdot 7$ \\
\hline D & $\mathbf{R}$ & $\begin{array}{l}\text { UT } \\
\text { LT }\end{array}$ & $\begin{array}{l}22 \cdot 12 \pm \cdot 12 \\
32 \cdot 87 \pm \cdot 40\end{array}$ & $\begin{array}{l}22 \cdot 75 \pm \cdot 26 \\
32 \cdot 37 \pm \cdot 42\end{array}$ & $\begin{array}{l}2 \cdot 8 \\
1 \cdot 5\end{array}$ \\
\hline $\mathbf{E}$ & $\mathbf{R}$ & UT & $26 \cdot 87 \pm \cdot 35$ & $27 \cdot 75 \pm \cdot 46$ & $3 \cdot 3$ \\
\hline
\end{tabular}

This analysis shows that the most striking calibre changes took place in those eyes in which the initial tensions were high. It was in these cases that the greatest difference between the higher and lower ocular tension was encountered, so it is not possible to state whether the vascular dilatation occurs pari passu with increases in intra-ocular pressure, or whether, as the tension rises, there is a critical level beyond which, a dilatation commences. There are theoretical reasons for believing that the latter state of affairs prevails and the point is discussed later.

The less marked changes occurring in eyes with the lower initial tensions, which were more marked on the venous side, are believed to have a physiological basis. The fact that calibre changes of a similar degree in both arteries and veins occur in the control group supports this view. It may be recalled that Kleinert found calibre changes of both arteries and veins in the episclera of glaucomatous patients and normal controls. The venous 
side of the general circulation especially is known to respond to physiological changes such as alterations in temperature or in emotional states, and it is quite possible that the retinal vessels share in these changes.

(2) Size of Vessels showing Variations in Calibre.-As far as can be seen from examination of the photographs, any variation in calibre of the larger vessels was present to a similar degree in its smaller branches. In some cases small vessels in the vicinity of the disc of the size of the 4th or 5th branching of the main branches were found to show the calibre changes. (See vessel indicated by arrow in Figs $1(a)$ and $1(b)$, overleaf). This point is of considerable importance, for the main vascular resistance is known to reside not in vessels of the size of those which were actually measured but in the smaller arterioles and precapillaries. It may be well at this juncture to remember that in this study the retinal circulation alone has been considered and no knowledge of the much more extensive choroidal circulation has been gained.

(3) Relation of Changes in Calibre to General Hypertension and Arteriosclerosis.-It has been suggested that a patient suffering from raised systemic blood pressure, by virtue of the raised arterial pressure-head, should be able to maintain a better ocular circulation in conditions of raised ocular tension than a patient with a lower systemic blood pressure. This was first pointed out by Sulzer (1897) and there are many other clinical observations to support the findings (Bailliart, 1922; Gallois, 1933, 1935; Lauber, 1935; Gandolfi, 1939; Legrand, 1948; Weinstein and Foldes, 1953). Furthermore, arteriosclerosis of the retinal vessels, by rendering them less elastic, should influence the calibre changes found. This series is too small to allow any definite conclusions to be drawn regarding the effect of the general circulation on the changes. Most of the subjects, being in the higher age groups, had blood pressures and retinal vessel changes normal for their age. The study will have to be extended to glaucomatous cases which show (a) hypertension without arterial thickening and (b) arteriosclerosis without hypertension, before the effect of the general circulation on glaucoma can be established.

\section{Discussion}

It has previously been established that when the ocular tension rises purely local pressure changes take place in the intra-ocular arteries and veins. These pressure changes are of considerable importance in maintaining the ocular circulation. The results of the present investigation probably indicate that there is a further mechanism whereby the circulation is protected: $v i z$., a dilatation of the intra-ocular vessels which facilitates the blood flow by lowering the vascular resistance.

Although these two compensatory mechanisms may function together, it is possible that the vascular dilatation is more in evidence at the higher tension levels. In the more moderate degrees of raised tension the local rise of both the intra-ocular venous and arterial pressures would seem to be 


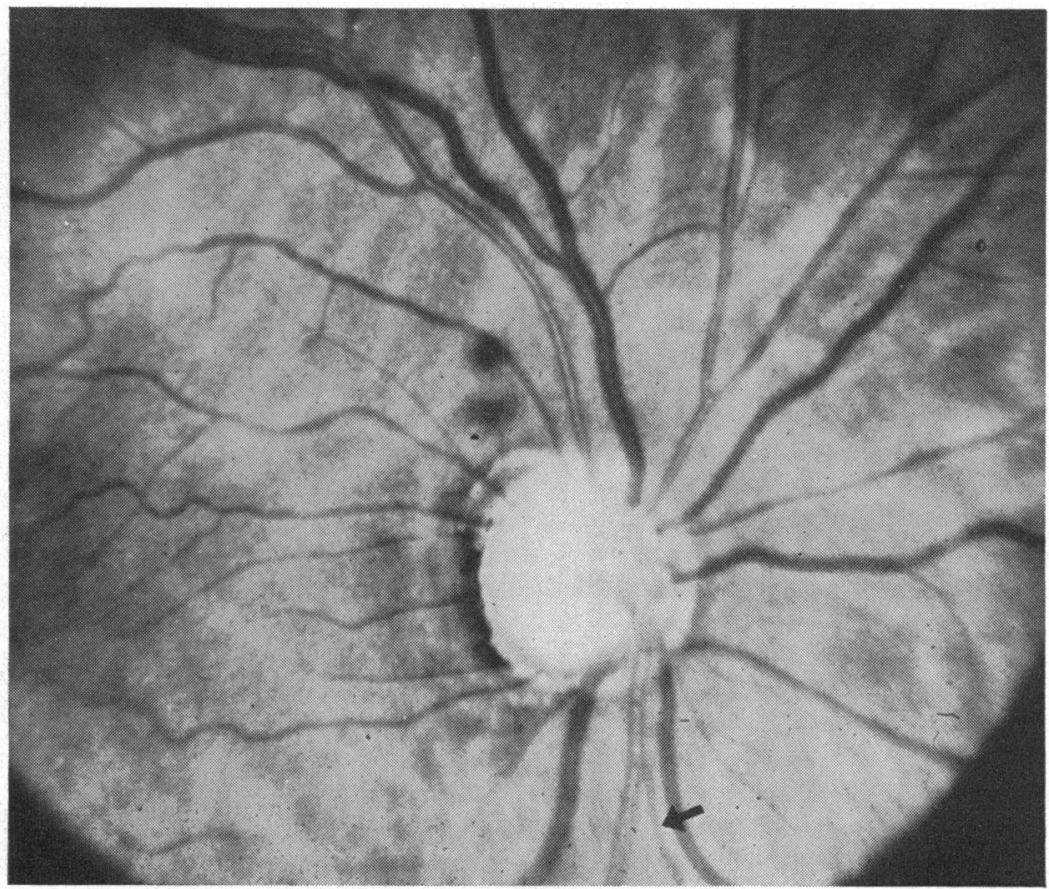

Fig. 1(a).-Fundus of a case of chronic simple glaucoma (ocular tension $73 \mathrm{~mm}$.

$\mathrm{Hg}$ ). Both arteries and veins are dilated.

sufficient to overcome the circulatory embarrassment and maintain an adequate blood flow. If the ocular pressure becomes progressively higher, however, this mechanism will become less and less effective. The reason for this is that the pressure-gradient or difference between the pressure-head (or available arterial pressure) and the outflow (or intra-ocular venous) pressure becomes less as the intra-ocular pressure rises. For, although the venous pressure can be progressively raised so as just to surmount the ocular pressure, the arterial pressure is limited by the pressure in the ophthalmic artery. If an extreme case be taken, if the ocular pressure approximates to the mean arterial pressure the pressure-gradient must be extremely small. If, therefore, in the higher ranges of ocular tension the mechanism of a " rise of local pressure" is less effective, it is suggested that the second mechanism, the "dilatation of the intra-ocular vessels" becomes increasingly important. It has been stated that for any given pressure-gradient more blood must flow when the vessels are dilated than when they are constricted, and a very small increase in calibre would be sufficient to lower the vascular resistance and greatly to improve the ocular circulation.

The experimental work of Porsaa (1941) and Linnér (1952) seems to bear directly on the results of the present study. In these experiments the intraocular pressure remained constant, or nearly so, but the pressure-gradients 


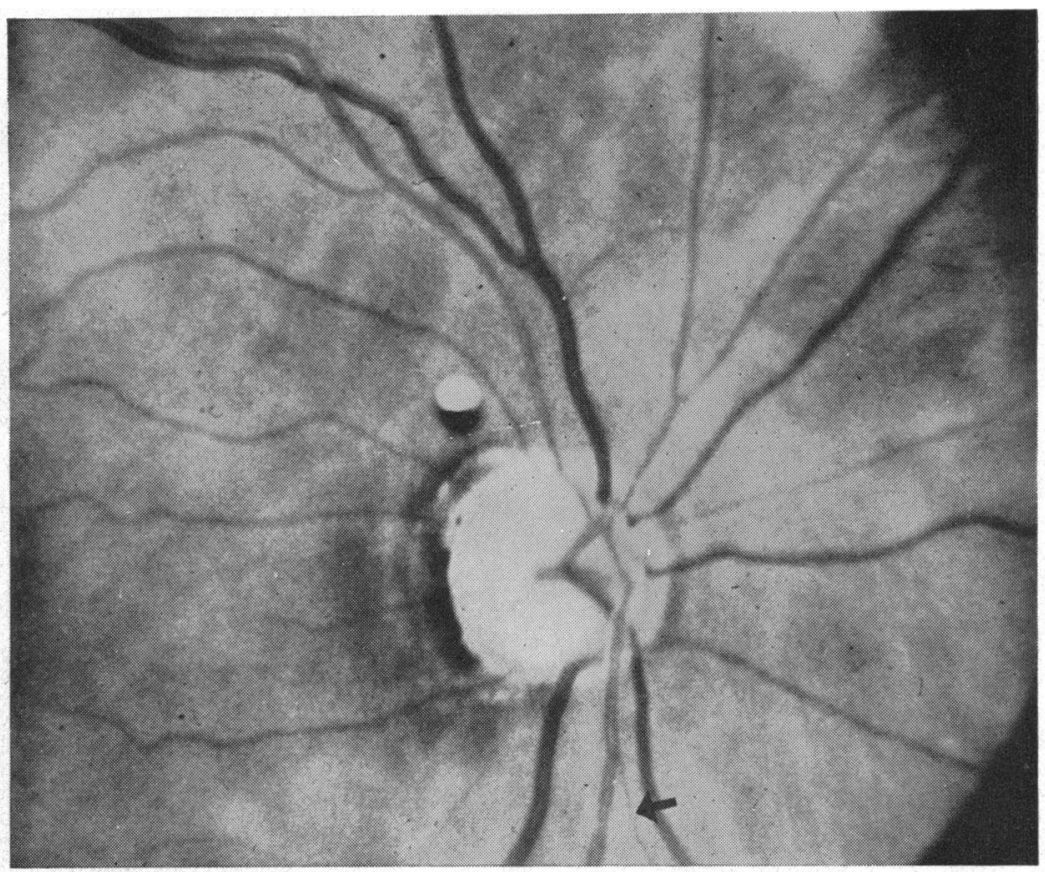

Fig. 1(b). - The same fundus with the tension reduced by operation to $22 \mathrm{~mm}$. $\mathrm{Hg}$; arrows indicate a very small artery which shows the same calibre reduction as the larger vessels.

in the intra-ocular vessels and the vascular resistance inside the eye were varied in different series of experiments.

Amongst Porsaa's studies are measurements of the calibre of the retinal vessels when the resistance to blood flow was varied. The resistance was increased by raising the pressure of the cerebro-spinal fluid and thereby compressing the retinal veins in the optic nerve sheath. Porsaa found in most instances that the obstruction to the flow was associated with a dilatation of both arteries and veins. In both sets of vessels the variation in calibre ranged from 10 to 30 per cent.

Other studies include the measurement of the retinal vessels when the pressure-gradient had been reduced by profound reduction of the pressurehead by lowering the general blood pressure. Whatever the means by which this reduction in blood pressure was effected, whether by acetylcholine, faradic stimulation of the depressor nerve, cardiac inhibition or by bleeding, the result was the same, namely a dilatation of the retinal vessels. Furthermore, this dilatation was shown by Porsaa to be a local ocular reaction coming on after the fall in systemic blood pressure and not part of it.

Linner measured the volume flow through the uveal circulation. $\mathrm{He}$ found that ligation of the carotid, which reduced the blood pressure by 53 per cent. only effected a reduction in blood flow by 19 per cent. Linnér 
suggests that there is a compensatory mechanism whereby a reduction of the vascular resistance is effected by a dilatation of the smaller arterioles of the uveal tract.

The cerebral circulation in conditions of raised cerebro-spinal fluid pressure has many features common to the circulation in the glaucomatous eye. Both sets of vessels are enclosed in rigid casings and in both the pressure of the surrounding fluid is transmitted to the interior of the vessels. The cerebral circulation is, moreover, more amenable to experimental study, so that a brief account of certain relevant findings in the field will be given.

The classical studies of the calibre changes of pial vessels are those of Wolff and Forbes (1928). They made direct observations through a transparent window let into the cranium of an animal. When the cerebro-spinal fluid pressure was raised no change in the pial vessels occurred until a height four or five times the normal was reached. As the pressure was increased beyond this point a slowing of the blood in the veins was observed. There followed a dilatation of the veins, then a dilatation of the arteries, and finally, when the pressure had been sufficiently increased, an emptying of the arteries and complete cessation of the blood flow.

The studies of the circulation in the eye and brain just described seem to support the original hypothesis, namely, that in glaucoma the intra-ocular circulation is first adjusted by means of pressure changes in the vessels and is augmented by a dilatation of the intra-ocular vessels. Should the intraocular pressure approximate even nearer to the pressure in the ophthalmic artery, one would expect to find, as did Duke-Elder (1926) in his experimental studies, an actual collapse of the intra-ocular vessels. This obliteration of the vessels has not been observed clinically in chronic glaucoma but may occur in absolute glaucoma. One such eye for example (not included in this series because it was sightless), in which the tension was over $90 \mathrm{~mm}$. $\mathrm{Hg}$, had almost complete obliteration of all the arteries at the disc during diastole. This eye, as is common in the more advanced cases of absolute glaucoma, developed cataract, so that the state of the vessels in extreme degrees of tension has not yet been ascertained.

The actual cause of the vascular dilatation can only be conjectured. An increase in vascular pressures would seem to be unlikely because in glaucomatous subjects a rise of pressure inside the blood vessels would be compensated by a comparable increase of pressure outside them. A more likely solution would seem to be that the circulatory embarrassment leads to a lack of oxygen or an excess of carbon dioxide acting directly on the walls of the vessels, and as elsewhere in the body, leading to vasodilatation.

\section{Summary}

(1) A photographic study has been made of the calibre changes in the retinal vessels occurring in chronic glaucoma simplex.

(2) A comparison was made by photographing the retinal vessels when 
the tension was high and again after the tension had been lowered by miotics or operation in a series of cases with differing degrees of raised tension. All cases had moderate or good retinal function.

(3) The changes were most marked in cases with the highest initial tension. These eyes were found to have a dilatation of both arteries and veins when the tension was raised.

(4) The dilatation is thought to be a local compensatory mechanism whereby the blood flow through the organ is improved by lowering the vascular resistance. It is most likely to come into play in the higher degrees of raised ocular tension.

(5) Calibre variations of a less degree were found in the test cases with lower tension and in the controls. These are thought to have a physiological basis.

I should like to express my thanks to Dr. Peter Hansell and to the staff of the Dept. of Medical Illustration at the Institute of Ophthalmology for their skill in producing the accurate pairs of photographs on which this work entirely depends.

My thanks are also due to Sir Stewart Duke-Elder and Dr. M. Langham for their helpful criticism and to Mr. J. Ridge for much good advice on the statistical presentation.

\section{REFERENCES}

Bailliart, P. (1922). Ann. Oculist. (Paris), 159, 432.

(1953). "Affections vasculaires de la rétine". Doin, Paris.

and Magitot, A. (1925). Ann. Oculist. (Paris), 162, 729.

DoBree, J. H. (1953). British Journal of Ophthalmology, 37, 293. - (1954). Ibid., 38, 500.

Duke-Elder, S. (1926). Ibid., 10, 513. (1940). "Text-book of Ophthalmology ", vol. 3, p. 3367. Kimpton, London.

ESPILDORA-LuQue, C. (1948). In " Modern Trends in Ophthalmology", ed. A. Sorsby, vol. 2, p. 153. Butterworth, London.

GalloIs, J. (1933). Bull. Soc. Ophtal. Paris, 45, 110. (1935). Ibid., 47, 165.

Gandolfi, C. (1939). Ann. Ottal., 67, 433.

Hill, L. (1913). Proc. roy. Soc. Med., 6 (Sect. Ophthal), 31. and Flack, M. (1912). Proc. roy. Soc. B, 85, 439.

Kleinert, H. (1954). v. Graefes Arch. Ophthal., 156, 68.

Kronfeld, P. C., McGarry, H. I., and Smith, H. E. (1943). Amer. J. Ophthal., $26,245$.

Lauber, H. (1935). Z. Augenheilk., 87, 65.

LEGRAND (1948). Bull. Soc. belge Ophtal., No. 88, p. 258.

LINNÉR, E. (1952). Acta physiol. scand., 26, 70.

PorsaA, K. (1941). Acta ophthal. (Kbh.), Suppl. 18.

Starling, E. H. (1913). Proc. roy. Soc. Med., 6 (Sect. Ophthal.), 44.

Sugar, H. S. (1948). Amer. J. Ophthal., 31, 1193. (1951). "The Glaucomas". Mosby, St. Louis.

Sulzer, D. E. (1897). Ann. Oculist. (Paris), 117, 81.

WeInstrin, P. (1935). Arch. Ophthal. (Chicago), 13, 181.

and Foldes, J. (1953). "Glaucoma-Pathology and Therapy". Mosby, St. Louis.

Wolff, H. G., and Forbes, H. S. (1928). Arch. Neurol. Psychiat., 20, 1035. 